\title{
Impacted Third Molars and Its Propensity to stimulate External Root Resorption in Second Molars: Comparison of Orthopantomogram and Cone Beam Computed Tomography
}

\author{
'Zeena V D'Costa, ${ }^{2}$ Junaid Ahmed, ${ }^{3}$ Ravikiran Ongole, ${ }^{4}$ Nandita Shenoy, ${ }^{5}$ Ceena Denny, ${ }^{6}$ Almas Binnal
}

\section{ABSTRACT}

Aim: This study was designed to compare the efficiency of conebeam computed tomography (CBCT) with panoramic radiography to discern external root resorption (ERR) in second molars.

Materials and methods: This was a retrospective study with a sample size of 50 participants who had a total of 120 impacted third molars visible on panoramic radiographs and CBCT images. The presence of ERR on the neighboring second molar was assessed and the position of impacted third molar was determined using Pell and Gregory classification. The ERR was registered according to Al-Khateeb and Bataineh's criteria. The location and severity were assessed by Ericson et al criteria, and grading of ERR was done as per the criteria given by Nemcovsky.

Results: The CBCT was able to locate and identify extremely large number of cases with ERR on second molars in comparison with the panoramic radiographs. Based on Pell and Gregory classification, position B was most common. The ERR on second molars was most commonly seen at the cervical region. Most of the cases had mild severity. As per grading mentioned by Nemcovsky, maximum number of cases were given grade $A$ followed by grade $B$.

Conclusion: According to our study and considering the threedimensional information obtained from $C B C T$, we found that ERR was better detected with CBCT.

Clinical significance: If on panoramic radiographs, a close contact is detected between the second molar and an impacted third molar, CBCT can be advised taking into account the "risk vs reward ratio."

Keywords: Cone beam computed tomography, Impacted, Panoramic, Radiography, Root resorption.

How to cite this article: D'Costa ZV, Ahmed J, Ongole R, Shenoy N, Denny C, Binnal A. Impacted Third Molars and Its Propensity to stimulate External Root Resorption in Second Molars: Comparison of Orthopantomogram and Cone Beam Computed Tomography. World J Dent 2017;8(4):281-287.

Source of support: Nil

Conflict of interest: None

\footnotetext{
${ }^{1-6}$ Department of Oral Medicine and Radiology, Manipal College of Dental Sciences, Manipal University, Mangaluru, Karnataka India

Corresponding Author: Junaid Ahmed, Department of Oral Medicine and Radiology, Manipal College of Dental Sciences Manipal University, Mangaluru, Karnataka, India, Phone: +919901470120, e-mail: junaid.ahmed@manipal.edu
}

\section{INTRODUCTION}

A tooth can be said to be impacted when it has been unerupted, either partially or completely, in the oral cavity and is known to be positioned against the adjacent tooth, soft tissue, or bone so that it is interrupted and is unlikely to erupt further. ${ }^{1}$

Impacted wisdom teeth account for $98 \%$ of all impacted teeth. ${ }^{2}$ The classic distribution in order of frequency of impaction of permanent teeth is observed in the following descending order: Mandibular third molars, maxillary third molars, maxillary canines, maxillary and mandibular premolars, maxillary incisors, mandibular canines, mandibular incisors, maxillary and mandibular first molars, and maxillary and mandibular second molars. ${ }^{3,4}$

Some of the impacted third molars remain asymptomatic for years and do not cause any clinical problem, ${ }^{5-7}$ and some may cause various symptoms and pathologies, such as pain, swelling, cheek ulceration, distal caries, bone loss, odontogenic cysts, benign or malignant tumors, systemic infections, and root resorption of adjacent teeth. ${ }^{8-13}$

Resorption of the roots of adjacent teeth can occur because of eruption pressure of the third molar or the impacted teeth might get embedded in bone for many years, and as they make an attempt to erupt, they sometimes cause considerable pressure on the roots of neighboring teeth, causing resorption, ${ }^{14}$ and this type of resorption of roots of adjacent teeth is termed as external root resorption (ERR).

External root resorption occurs as a result of changes in the osteoclastic activity leading to destruction of mineralized dental tissue. ${ }^{15}$ Physiologically, it is noted when the primary dentition exfoliates. ${ }^{15}$

The known risk factor for tooth resorption is the mechanical force due to the superimposition of the third molar, and the inflammation of the periodontium may further complicate the condition ${ }^{16}$ or might even secrete the inflammatory mediators that assign the osteoclast toward resorption of the mineralized tissue by stimulating the reduced dental epithelium of the impacted tooth. ${ }^{17,18}$

External root resorption usually does not present with any signs and symptoms. ${ }^{19}$ Hence, it is diagnosed based on its detection during radiographic examination $\mathrm{s}^{20}$ and 
to preserve the involved teeth; the key factor is early diagnosis. $^{21}$

The panoramic radiograph is often the initial radiograph for the evaluation of impacted teeth as it provides information about all the teeth in both arches and the surrounding structures and has low radiation exposure. ${ }^{6,22}$ However, panoramic radiograph has few drawbacks, such as distortion, magnification, and loss of some details. ${ }^{6,23,24}$

Traditional two-dimensional (2D) imaging of threedimensional (3D) anatomic structures has long posed a problem in the diagnosis and management of impactions, and when there is a need of observing an impacted third molar and its proximity to the neighboring structures, cone beam computed tomography (CBCT) has been taken into consideration. ${ }^{25,26}$ The CBCT has heralded winds of change and revolutionized the world of diagnostic dental imaging!

Cone beam computed tomography is considered as the desirable tool for detecting subtle changes, such as ERR because it helps in assessing the region of interest in all the planes and has relatively less amount of radiation when compared with CT scans. ${ }^{27}$

Most of the available data on ERR have come from case reports ${ }^{28-30}$ and retrospective studies of panoramic and periapical radiographs, 11,17,27,31-34 and very few studies have been performed comparing panoramic imaging with CBCT, and the information available is still limited.

Taking into consideration the importance of diagnosis of ERR radiographically, the study aimed to compare panoramic radiography and CBCT for determining ERR of second molars.

\section{MATERIALS AND METHODS}

A retrospective study was conducted with a sample size of 50. After obtaining permission from the Institutional Scientific and Ethics Committee, the CBCT volumes and panoramic radiographs from the archives of Oral Medicine and Radiology from November 2013 up to December 2015 were screened.

Patient's demographic data, such as age and gender were noted.

The database of the patients who have undergone preoperative examination of one or more impacted third molars (panoramic radiography and $\mathrm{CBCT}$ ), and the $\mathrm{CBCT}$ and panoramic scans in which the area of interest is clear (without any artifact) were included in the study.

Third molars with evidence of root development which is less than two-thirds were excluded from this study. Patients with radiologic evidence of intraosseous pathologic features (e.g., cysts or tumors) associated with the third molars and extensive caries lesions on the second molars were also excluded from this study. In some situations, the presence of high-density materials (e.g., restoration, intracanal post, or orthodontic or surgical screw) can produce beam-hardening artifacts, jeopardizing the CBCT image, as well as artifacts in panoramic radiographs can affect the quality. If these artifacts were superimposed on the second molar roots, precluding the correct diagnosis, the image was excluded.

The teeth were localized (upper or lower jaw) and the position of the impacted teeth was classified using Pell and Gregory A, B, and C classification which is as follows ${ }^{35}$ :

- Position A: The highest position of the impacted tooth is on a level with or above the occlusal plane of the second molar.

- Position B: The highest position of the impacted tooth is below the occlusal plane but above the cervical level of the second molar.

- Position C: The highest position of the impacted tooth is below the cervical level of the second molar.

Al-Khateeb and Bataineh's ${ }^{11}$ criterion was used to determine the presence of ERR, which stated that ERR is present when evidence of loss of substance in the root of an adjacent second molar was detected.

Based on the location, ERR was classified as cervical, middle, or apical root third (Fig. 1), and severity was graded as per the criteria given by Ericson et $\mathrm{al}^{36}$ which is as follows: Slight (very less amount of involvement of dentin thickness), moderate (half of the dentin is involved), and severe (pulp cavity is involved) (Fig. 2).

Grading of ERR was done as per the criteria mentioned by Nemcovsky: (a) No evidence of any resorption; (b) irregular defect noted on the root surface not exceeding $2 \mathrm{~mm}$ depth; (c) obvious irregularities noted exceeding $2 \mathrm{~mm}$, with the involvement of the pulp but the root form is maintained; $(d)$ resorption involving the pulp with loss of root shape; and (e) total root resorption. ${ }^{18}$

\section{Statistical Analysis}

Statistical analysis was performed using Chi-squared test and by utilizing the Statistical Analysis System (Statistical Package for the Social Sciences version 20.0).

\section{RESULTS}

This study included 27 males and 23 females. In 50 patients, 178 third molars were assessed. Among 178 molars, 120 were impacted. Out of 84 maxillary molars, 39 were impacted, and out of 94 mandibular molars, 81 were impacted. The prevalence rate of impaction was more for mandibular third molars which was $86.17 \%$ and for maxillary molars was $46.43 \%$.

According to Pell and Gregory A, B, C classification, Position B was more prevalent, followed by Positions A and C (Graph 1). 


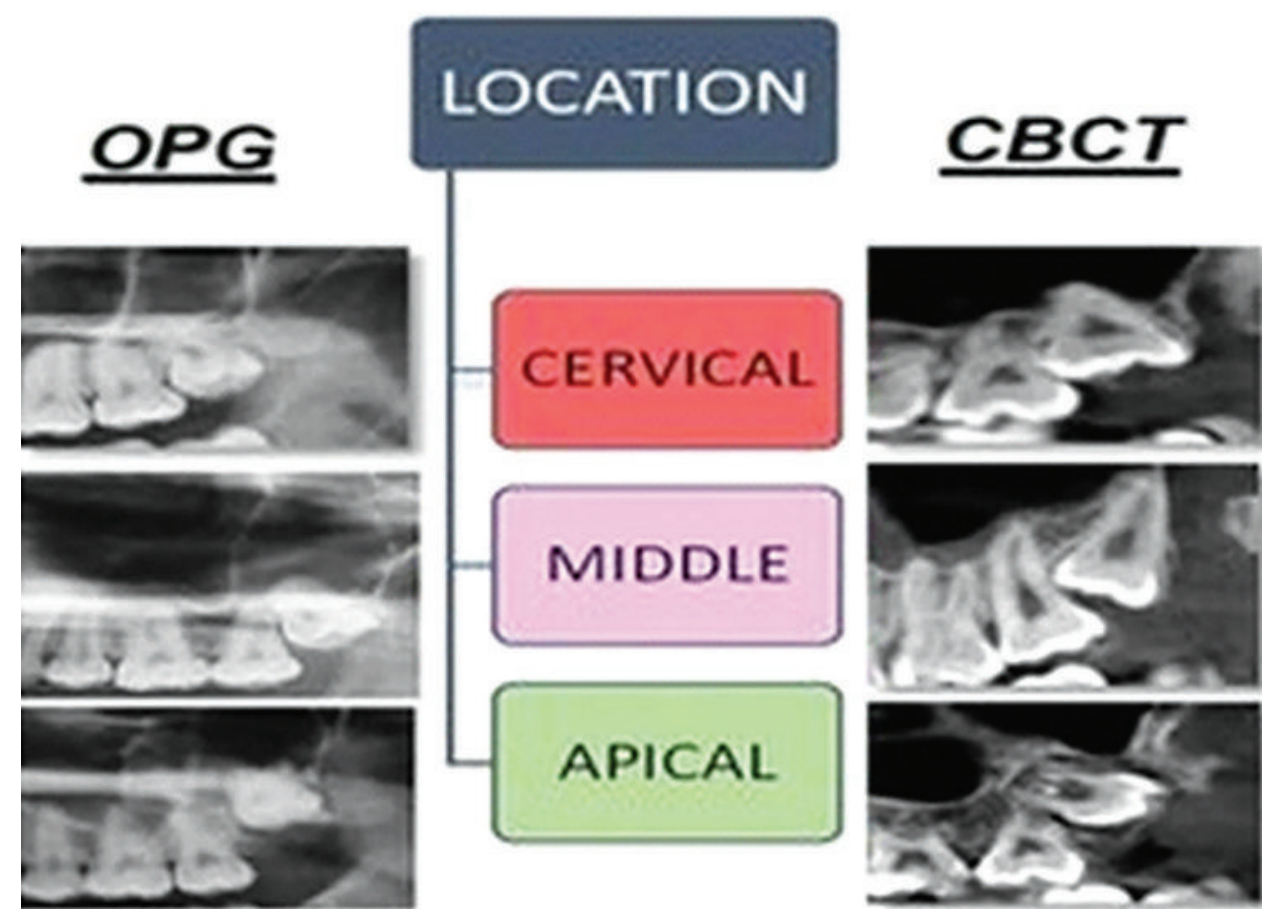

Fig. 1: Location of ERR on OPG and CBCT
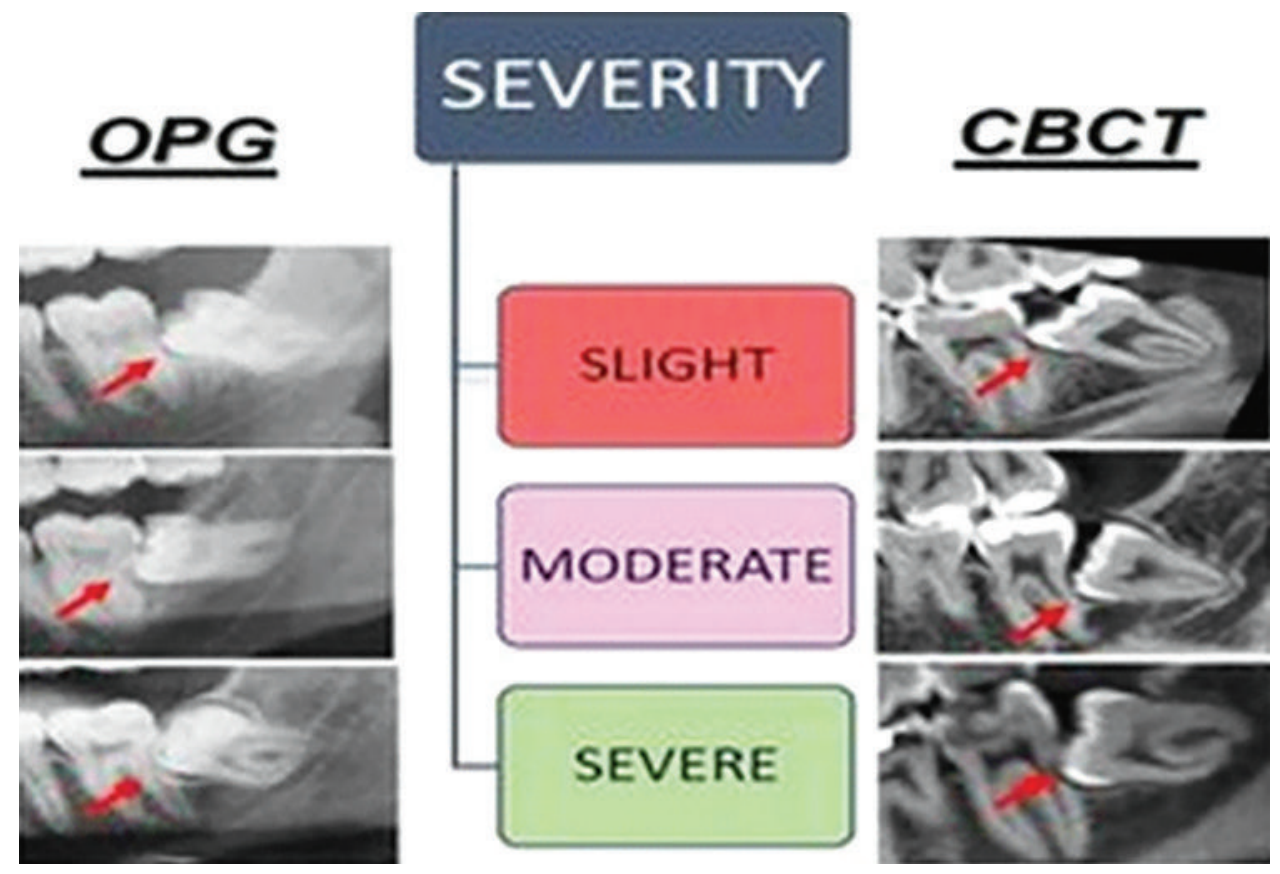

Fig. 2: Severity of ERR on OPG and CBCT

Further, comparing the location, severity, and grading among CBCT and orthopantomogram (OPG) images, it was found that both the CBCT and OPG images revealed similar findings (Graphs 2 to 4 ):

- Location of ERR: Cervical > middle > apical

- Severity of ERR: Slight $>$ moderate

- Grading of ERR: Grade $\mathrm{A}>$ grade $\mathrm{B}>$ grade $\mathrm{C}$

McNemar's test was used for comparing ERR in both $\mathrm{CBCT}$ and OPG. ${ }^{37}$ The CBCT images showed significantly more ERR when compared with panoramic radiographs
(Table 1). The prevalence of ERR from the CBCT images was $52.5 \%$ and from the panoramic images was $13.3 \%$.

Considering ERR detected in CBCT images as the gold standard and ERR in OPG as the parameter, our study had $23.80 \%$ sensitivity and $98.20 \%$ specificity.

\section{DISCUSSION}

Evidence of break in integrity on the surface of second molar that is placed adjacent to a impacted third molar can be due to either dental caries or ERR. 11,17,27,34,38 


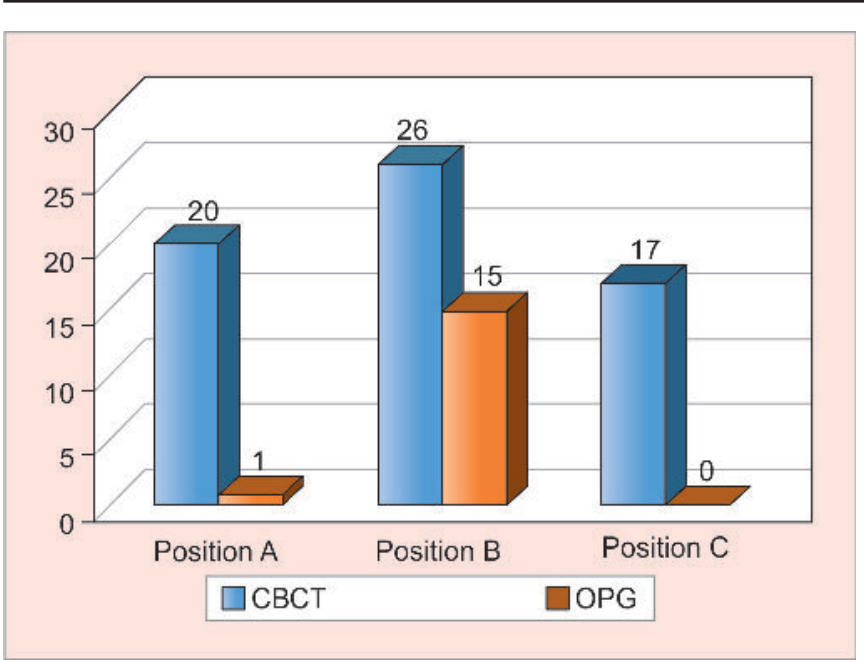

Graph 1: Position of impacted third molars

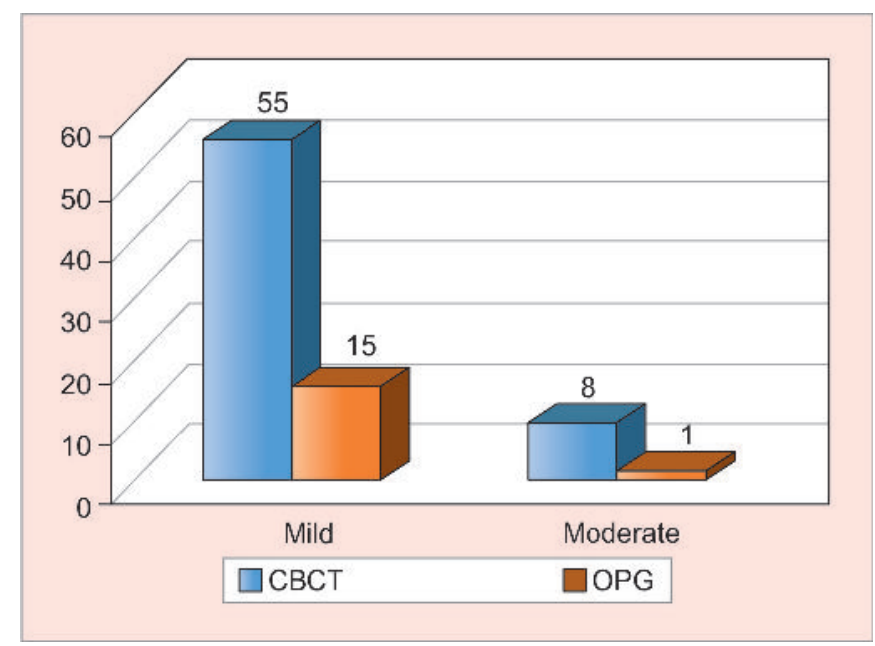

Graph 3: Comparison of the severity of ERR between $\mathrm{OPG}$ and $\mathrm{CBCT}$

Table 1: McNemar's test comparing CBCT and OPG

\begin{tabular}{llll}
\hline \multicolumn{3}{c}{ Count } & \\
\hline & \multicolumn{2}{c}{ OPG ERR } & \\
\cline { 2 - 3 } & Absent & Present & Total \\
\hline $\begin{array}{l}\text { Cone beam computed } \\
\text { tomography ERR }\end{array}$ & & & \\
Absent & 56 & 1 & 57 \\
Present & 48 & 15 & 63 \\
\hline Total & 104 & 16 & 120 \\
\hline
\end{tabular}

\begin{tabular}{lll}
\hline & Chi-square test \\
\hline & Value & Exact sig. (2-sided) \\
\hline McNemar's test & $0.000^{*}$ \\
$\mathrm{~N}$ of valid cases & 120 & \\
\hline *Binomial distribution used &
\end{tabular}

Furthermore, carious lesions are mostly symptomatic when compared with ERR, which is usually asymptomatic and aseptic, unless the pulp cavity has been involved or the lesion has been secondarily infected. ${ }^{39}$

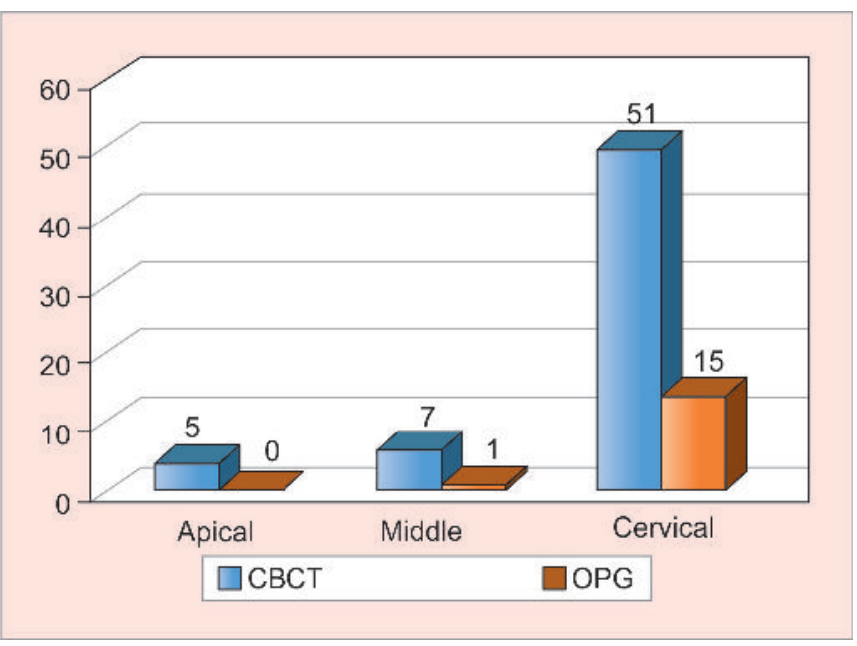

Graph 2: Comparison of the location of ERR between OPG and CBCT

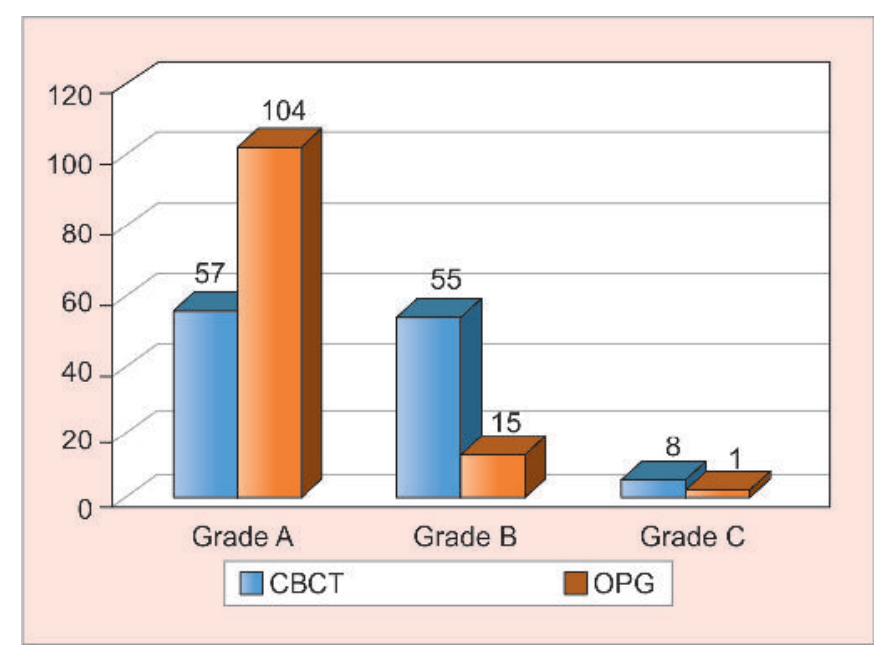

Graph 4: Comparison of the grading of ERR between OPG and CBCT

Several studies have proved that 3D imaging provides accurate diagnoses in determining ERR associated with the impacted teeth. ${ }^{40-42}$

To detect ERR, radiographs have to be interpreted with extreme care. The CBCT aids in the detection of early diagnosis of root resorption as well as being capable of determining the extent and progress of root resorption, which is slightly detected on 2D radiographs. ${ }^{43}$

Various studies conducted using periapical and panoramic radiographs have investigated the presence of ERR. ${ }^{11,17,27,31,32,34,44}$ However, most of the studies showed a low prevalence rate of ERR $(0.3-7 \%)$. $11,27,32,33$

Knutsson et $\mathrm{al}^{31}$ evaluated 666 patients and reported root resorption of second molars only in $1 \%$ of the cases.

Later, Nemcovsky et $\mathrm{al}^{34}$ conducted a study on 186 periapical radiographs and reported a greater prevalence rate of $24.2 \%$ of resorption. According to them, the greater prevalence rate of root resorption was because of their choice of completely nonerupted third molars as 
partially erupted teeth extend less inflammation and are also known to decrease the pressure on adjacent tooth.

A study performed by Nemcovsky et $\mathrm{al}^{18}$ on eight teeth which were previously diagnosed with ERR using intraoral radiography revealed resorption in all the teeth and thus proved that radiographic diagnosis appears to be reliable.

Nitzan et $\mathrm{al}^{33}$ conducted a radiographic study on 199 cases and found that only 15 cases reported with root resorption, and the least affected region was cervical. In our study, the least affected region was apical and most commonly affected region was cervical.

The ERR lesions frequently detected in the cervical region of second molars highlight the fact that the cervical portion of the root is more susceptible to the inflammatory process that culminates in ERR. ${ }^{33}$ However, the study conducted by Nemcovsky et $\mathrm{al}^{34}{ }^{34}$ who evaluated only completely unerupted third molars, stated that the apical region of the adjacent second molar was the most susceptible to ERR. Their study also revealed that pressure on the periodontal ligament and roots of the second molar is decreased when third molars are partially erupted.

The detection of ERR on second molars was 4.3 times greater when 3D images were used as per the study conducted by Oenning et al. ${ }^{40}$ The impacted tooth was classified as per Winter's classification. The study revealed that CBCT images $(n=43 ; 22.88 \%)$ diagnosed more ERR than panoramic radiographs $(\mathrm{n}=10 ; 5.31 \%)$, and even our study revealed similar results. They also stated that mesioangular and horizontal inclinations were more likely to cause ERR. ${ }^{40}$

Oenning et $\mathrm{al}^{45}$ determined the prevalence rate of ERR as $49.43 \%$ in a study that recorded ERR in mesially inclined impacted third molars on CBCT scans. Their study stated that Position C of third molars according to Pell and Gregory classification is more prone for ERR. ${ }^{45}$ However, according to our study, Position B is more prone for ERR.

The study published by Sarrafpour et $\mathrm{al}^{46}$ stated that eruptive tooth movements do not cease with completion of root formation and closure of the apex, which implies that a retained tooth continues to exert pressure on the adjacent tooth, stimulating and progressing root resorption. In cases of resorption, third molars should be advised for surgical removal. However, till date, there is no consensus guideline for the removal of impacted third molars that are asymptomatic. ${ }^{47,48}$

The limitation of the present study was that ERR was diagnosed only radiographically without correlating with the clinical signs and symptoms, and ERR lesions were not confirmed histologically. To provide better scientific evidence, longitudinal research must be conducted by correlating clinical, radiological, and histologic evaluation of the second molars and their relation to the unerupted third molars.

The 2D imaging of 3D anatomic structures has posed problems in the diagnosis and management of impactions, ${ }^{49}$ and multiplanar imaging, such as CBCT has brought in a paradigm shift in the diagnosis and management of dental impactions. With the aid of CBCT, we can speculate the degree of ERR and determine the prognosis of the adjacent teeth.

\section{CONCLUSION}

Most of the impacted third molars cause ERR of adjacent second molars. This resorption can be better detected on CBCT in comparison with OPG. However, in all cases of third molar impaction, it is not necessary to recommend CBCT just for the evaluation of ERR and the risk associated with the CBCT exposure should be taken into account. However, if we consider the "risk vs reward ratio" and if in case there are more benefits by recommending $\mathrm{CBCT}$, then it should be advised. Thus, if on panoramic radiographs, a close contact is detected between the impacted third molar and adjacent second molar, CBCT can be advised taking into account the "risk $v$ s reward ratio."

\section{REFERENCES}

1. Janakiraman EN, Alexander M, Sanjay P. Prospective analysis of frequency and contributing factors of nerve injuries following third-molar surgery. J Craniofac Surg 2010 May;21(3): 784-786.

2. Gbotolorun OM, Olojede AC, Arotiba GT, Ladeinde AL, Akinwande JA, Bamgbose BO. Impacted mandibular third molars: presentation and postoperative complications at the Lagos University Teaching Hospital. Nig Q J Hosp Med 2007 Jan-Mar;17(1):26-29.

3. Ericson S, Kurol J. Resorption of incisors after ectopic eruption of maxillary canines: a CT study. Angle Orthod 2000 Dec;70(6):415-423.

4. Quirynen M, Op Heij DG, Adriansens A, Opdebeeck HM, van Steenberghe D. Periodontal health of orthodontically extruded impacted teeth. A split-mouth, long-term clinical evaluation. J Periodontol 2000 Nov;71(11):1708-1714.

5. Ventä I, Ylipaavalniemi P, Turtola L. Long-term evaluation of estimates of need for third molar removal. J Oral Maxillofac Surg 2000 Mar;58(3):288-291.

6. Bishara SE, Andreasen G. Third molars: a review. Am J Orthod 1983 Feb;83(2):131-137.

7. Knutsson K, Brehmer B, Lysell L, Rohlin M. Asymptomatic mandibular third molars: oral surgeons' judgment of the need for extraction. J Oral Maxillofac Surg 1992 Apr;50(4): 329-333.

8. Bataineh AB, Albashaireh ZS, Hazzaa AM. The surgical removal of mandibular third molars: a study in decision making. Quintessence Int 2002 Sep;33(8):613-617.

9. Almendros-Marques N, Berini-Aytes L, Gay-Escoda C. Influence of lower third molar position on the incidence of preoperative complications. Oral Surg Oral Med Oral Pathol Oral Radiol Endodontol 2006 Dec;102(6):725-732. 
10. McArdle LW, McDonald F, Jones J. Distal cervical caries in the mandibular second molar: an indication for the prophylactic removal of third molar teeth? Update. Br J Oral Maxillofac Surg 2014 Feb;52(2):185-189.

11. Al-Khateeb TH, Bataineh AB. Pathology associated with impacted mandibular third molars in a group of Jordanians. J Oral Maxillofac Surg 2006 Nov;64(11):1598-1602.

12. Doğan N, Orhan K, Günaydin Y, Köymen R, Okçu K, Uçok O. Unerupted mandibular third molars: symptoms, associated pathologies, and indications for removal in a Turkish population. Quintessence Int 2007 Sep;38(8):e497-e505.

13. Polat HB, Özan F, Kara I, Özdemir H, Ay S. Prevalence of commonly found pathoses associated with mandibular impacted third molars based on panoramic radiographs in Turkish population. Oral Surg Oral Med Oral Pathol Oral Radiol Endodontol 2008 Jun;105(6):e41-e47.

14. Tamse A. VI radiography and photography roentgenographic features of external root. Quintessence Int (Berl) 1982;1:51-55.

15. Mesgarani A, Haghanifar S, Ehsani M, Yaghub SD, Bijani A. Accuracy of conventional and digital radiography in detecting external root resorption. Iran Endod J 2014 Fall;9(4): 241-245.

16. Southam JC. Clinical and histological aspects of peripheral cervical resorption. J Periodontol 1967 Nov-Dec;38(6):534-538.

17. Yamaoka M, Furusawa K, Ikeda M, Hasegawa T. Root resorption of mandibular second molar teeth associated with the presence of the third molars. Aust Dent J 1999 Jun;44(2): 112-116.

18. Nemcovsky CE, Tal H, Pitaru S. Effect of non-erupted third molars on roots of approximal teeth. A radiographic, clinical and histologic study. J Oral Pathol Med 1997 Nov;26(10): 464-469.

19. Benenati FW. Root resorption: types and treatment. Gen Dent 1997 Jan-Feb;45(1):42-45.

20. Shokri A, Mortazavi H, Salemi F, Javadian A, Bakhtiari H, Matlabi H. Diagnosis of simulated external root resorption using conventional intraoral film radiography, CCD, PSP, and CBCT: a comparison study. Biomed J 2013 Jan-Feb;36(1):18-22.

21. Levander E, Bajka R, Malmgren O. Early radiographic diagnosis of apical root resorption during orthodontic treatment: a study of maxillary incisors. Eur J Orthod 1998 Feb;20(1):57-63.

22. Pursafar F, Salemi F, Dalband M, Khamverdi Z. Prevalence of impacted teeth and their radiographic signs in panoramic radiographs of patients referred to hamadan dental school in 2009. Avicenna J Dent Res 2011;3(1):21-27.

23. Mahesh MS, Mahima VG, Patil K. A comparative evaluation of film and digital panoramic radiographs in the assessment of position and morphology of impacted mandibular third molars. Indian J Dent Res 2011 Mar-Apr;22(2):219-224.

24. Kumar AN, Agrawal G, Agrawal A, Sreedevi, Kakkad A. Journey from $2 \mathrm{D}$ to $3 \mathrm{D}$ : implant imaging a review. Int J Contemp Dent Med Rev 2014;2014:091114.

25. Ghaeminia H, Meijer GJ, Soehardi A, Borstlap WA, Mulder J, Vlijmen OJ, Bergé SJ, Maal TJ. The use of cone beam CT for the removal of wisdom teeth changes the surgical approach compared with panoramic radiography: A pilot study. Int J Oral Maxillofac Surg 2011 Aug;40(8):834-839.

26. Matzen LH, Christensen J, Hintze H, Schou S, Wenzel A. Influence of cone beam CT on treatment plan before surgical intervention of mandibular third molars and impact of radiographic factors on deciding on coronectomy vs surgical removal. Dentomaxillofac Radiol 2013;42(1):98870341.
27. Akarslan ZZ, Kocabay C. Assessment of the associated symptoms, pathologies, positions and angulations of bilateral occurring mandibular third molars: is there any similarity? Oral Surg Oral Med Oral Pathol Oral Radiol Endodontol 2009 Sep;108(3):e26-e32.

28. Oles RD. Root resorption associated with impacted third molars. Oral Surg Oral Med Oral Pathol 1979 Sep;48(3):281.

29. Girdler NM. The unpredictability of impacted third molar development - the danger of passive observation. Br Dent J 1990 Feb 10;168(3):92.

30. Wang HY. Root resorption associated with impacted maxillary third molar. Oral Surg Oral Med Oral Pathol 1992 Jun;73(6):765-766.

31. Knutsson K, Brehmer B, Lysell L, Rohlin M. Pathoses associated with mandibular third molars subjected to removal. Oral Surg Oral Med Oral Pathol Oral Radiol Endod 1996 Jul;82(1):10-17.

32. van der Linden W, Cleaton-Jones P, Lownie M. Diseases and lesions associated with third molars. Review of 1001 cases. Oral Surg Oral Med Oral Pathol Oral Radiol Endod 1995 Feb;79(2):142-145.

33. Nitzan D, Keren T, Marmary Y. Does an impacted tooth cause root resorption of the adjacent one? Oral Surg Oral Med Oral Pathol 1981 Mar;51(3):221-224.

34. Nemcovsky CE, Libfeld H, Zubery Y. Effect of non-erupted 3rd molars on distal roots and supporting structures of approximal teeth. A radiographic survey of 202 cases. J Clin Periodontol 1996 Sep;23(9):810-815.

35. Lima CJ, Silva LC, Melo MR, Santos JA, Santos TS. Evaluation of the agreement by examiners according to classifications of third molars. Med Oral Patol Oral Cir Bucal 2012 Mar 1;17(2):e281-e286.

36. Ericson S, Bjerklin K, Falahat B. Does the canine dental follicle cause resorption of permanent incisor roots? A computed tomographic study of erupting maxillary canines. Angle Orthod 2002 Apr;72(2):95-104.

37. Pett MA. Nonparametric statistics for health care research: statistics for small samples and unusual distributions. Thousand Oaks (CA): Sage Publications; 2015.

38. Falci SG, de Castro CR, Santos RC, de Souza Lima LD, RamosJorge ML, Botelho AM, Dos Santos CR. Association between the presence of a partially erupted mandibular third molar and the existence of caries in the distal of the second molars. Int J Oral Maxillofac Surg 2012 Oct;41(10):1270-1274.

39. Fuss Z, Tsesis I, Lin S. Root resorption - diagnosis, classification and treatment choices based on stimulation factors. Dent Traumatol 2003 Aug;19(4):175-182.

40. Oenning AC, Neves FS, Alencar PN, Prado RF, Groppo FC, Haiter-Neto F. External root resorption of the second molar associated with third molar impaction: comparison of panoramic radiography and cone beam computed tomography. J Oral Maxillofac Surg 2014 Aug;72(8):1444-1455.

41. Alqerban A, Jacobs R, Souza PC, Willems G. In-vitro comparison of 2 cone-beam computed tomography systems and panoramic imaging for detecting simulated canine impaction-induced external root resorption in maxillary lateral incisors. Am J Orthod Dentofacial Orthop 2009 Dec;136(6):764.e1-764.e11.

42. Alqerban A, Jacobs R, Fieuws S, Willems G. Comparison of two cone beam computed tomographic systems versus panoramic imaging for localization of impacted maxillary 
canines and detection of root resorption. Eur J Orthod 2011 Feb;33(1):93-102.

43. Nodehi D, Pahlevankashi M, Moghaddam BN. Cone beam computed tomography functionalities in dentistry. Int J Contemp Dent Med Rev 2015;2015:040515.

44. Kahl B, Gerlach KL, Hilgers RD. A long-term, follow-up, radiographic evaluation of asymptomatic impacted third molars in orthodontically treated patients. Int J Oral Maxillofac Surg 1994 Oct;23(5):279-285.

45. Oenning AC, Melo SL, Groppo FC, Haiter-Neto F. Mesial inclination of impacted third molars and its propensity to stimulate external root resorption in second molars - a conebeam computed tomographic evaluation. J Oral Maxillofac Surg 2015 Mar;73(3):379-386.
46. Sarrafpour B, Swain M, Li Q, Zoellner H. Tooth eruption results from bone remodelling driven by bite forces sensed by soft tissue dental follicles: a finite element analysis. PLoS One 2013;8(3):e58803.

47. Mansuri S, Mujeeb A, Hussain SA, Hussain MA. Mandibular third molar impactions in male adults: Relationship of operative time and types of impaction on inflammatory complications. J Int Oral Health 2014 Apr;6(2):9-15.

48. Stephens RG, Kogon SL, Reid JA. The unerupted or impacted third molar - a critical appraisal of its pathologic potential. J Can Dent Assoc 1989 Mar;55(3):201-207.

49. Deepak C, Saravanan B, Kumar SK. CBCT - a paradigm shift in the management of dental impactions. Indian J Multidiscip Dent 2011;1(2):64-118. 